\title{
An Investigation of College Students' Green Consumption Behavior in China
}

\author{
Chih-Hsuan Huang ${ }^{1}$, Yi-Chun Huang ${ }^{2}$, Hong Jin ${ }^{1}$, Meng-Chen Lin ${ }^{1}$, Yu-Ping Wu ${ }^{1}$, Li Lee ${ }^{3 *}$ \\ ${ }^{1}$ School of Business Administration, Hubei University of Economics, No.8, Yanghu Avenue, Canglongdao \\ Development Zone, Jiangxia District, Wuhan, Hubeie, China. \\ 2 Department of Business Administration, National Kaohsiung University of Applied Sciences, No. 415, \\ Chien-Kung Rd., Kaohsiung City, Taiwan. \\ ${ }^{3}$ School of Management, Wuhan Institute of Bioengineering, No.1, Hanshi Road, Yangluo Development Zone, \\ Wuhan, Hubei, China.
}

*Corresponding author. Tel.: +86 27 89648757; email: Lisat23@163.com

Manuscript submitted March 20, 2017; accepted May 28, 2017.

doi: 10.17706/ijeeee.2017.7.4.280-286

\begin{abstract}
Rise of green consumption results from the change in consumers' purchase behavior in response to the deterioration of environmental resources, where they seek products and services that cause the least harm to the environment. It involves not only meeting consumer needs but also the consumption of products and services to further the protection of the environmental resources. This study aims to understand the green consumption views and practices of college students, as they are one of the important factors of China's future development. Further, it aims to improve the college students' overall quality of environmental protection. The green consumption behavior of the college students was investigated by using the Theory of Planned Behavior (TPB), which include four aspects; that is, green consumption attitude, subjective norms of green consumption, perception of green consumption behavior, and green consumption behavior. The results showed that the intentions of green consumption to college students were predicted by green attitude, green subjective norms, and green perceived behavioral control. In addition, behavioral intentions were to found to have a significant and positive relationship with actual behavior.
\end{abstract}

Key words: Green consumption, college student, relationship quality, theory of planned behavior.

\section{Introduction}

Green concepts usually include life, resources, environment, energy conservation, environmental protection, and sustainability. Green consumption involves a wide range of content, including not only green products but also the recovery of consumer goods, the effective use of energy, the living environment, the protection of species, etc. which reflect both producers of production and consumption [1]. It implies that the society's consumption should meet the safety and health demands of not just the current generation but also the future generations [2]. Green consumption involves three aspects: first, advocate consumers to use eco-friendly products or improve public health through green products. Second, at the end of the consumption process, ensure that garbage disposal does not cause environmental pollution [3]. Third, guide consumers to change their perception of consumption by inculcating respect for nature, pursuit of health, simultaneously, pursuit of quality of life, attention to environmental protection, and conservation of resources and energy to achieve sustainable consumption [1]. 
As green consumption covers all aspects of our lives, we hope to promote the green consumption among the youth in their daily life through the study of the behavior of college students' green consumption. However, this process is not easy, as it involves the transformation of consumer attitudes and real-life practices, and then, it affects the stakeholders of green consumption to promote the improvement of the socio-environmental resources [4]. In addition, as the current world population is growing, the expansion of human demand for environmental resources is increasing. Further, the worsening manmade ecological crisis and the depleting environmental resources cause the urgent need for environmental protection and the promotion of green consumption in China. The promotion of green consumer attitudes and the further practice of life are becoming more important. This requires green consumers to adopt the virtuous cycle of create and save resources, protecting the environment, and promoting sustainable development.

This paper considers the green consumption behavior of college students because the current college students are the backbone of China's future development, and the modern university students' acceptance ability and creativity are particularly strong and their speed of adaptation is high. Further, their importance in their peer groups cannot be ignored, as these students may be some of the most educated and influential within their families.

The theory of planned behavior (TPB) has been widely used in many areas of research, but for the discussions of college students in green consumption are still ambiguous. Further, the role of college students in the university is to enhance their cognitive ability and understanding of social development, and thus, they are highly conducive to social progress through green consumption recognition; however, their behavior is highly vulnerable. Subjective factors and other people's influence can control and influence individual behavior. The TPB theory consists of attitude, intention, subjective norms, which is suitable for the study of college students. Based on the above, the purpose of this study can be summarized as two points:

1) The study of college students' green consumption behavior will be investigated.

2) Through the analysis of the green consumption behavior of college students, the ways to promote college students towards green consumption and social sustainable development can be suggested in China.

\section{Relevant Literature}

According to the basic assumption of theory of planned behavior (TPB), the behavior of consumers is based on the control of the will and the thinking is systematic, in which it is determined whether the consumer is performing a particular act by its behavior [5], [6]. The behavioral intention is influenced by the attitude of the behavior, the subjective norm, and the perceived behavioral control. Attitude is a positive or negative assessment of the particular conduct. When the attitude of the individual towards a behavior is more positive, there is a higher intention of behavior. On the other hand, when the attitude of the individual to the behavior is more negative, the less likely to behave similarly [5], [7]-[9]. Subjective norms refer to the perception that the individual perceives the particular person's behavior, such as family or friends, and so on. When the society tends to support his/her behavior, the greater the motivation for personal compromise [5], [7]-[9], and his subjective norms are more intense, prompting him to produce the intention to engage in the act. Perceptual behavior control mainly refers to the individual's own understanding of the degree of difficulty in completing a particular act. When individuals feel that they have the ability to perform a particular act, the stronger the resources, the weaker the expected barrier, and the stronger the perceived control [7]-[9]. Therefore, according to the TPB, the three predictive variables that must be considered when predicting individual behavior are individual attitudes, subjective norms, and the degree of control of the behavior. Further, the more attitudes toward the act, the more the subjective norms 
support the individual in the act, the stronger the control of the behavioral perception behavior, and the stronger the intentions of the act [9], [10].

In the recent years, the TPB has been used in different areas of green consumer behavior analysis. There are many scholars in the green consumption areas such as green consumer market [11]; green hotel [12]; green organic products [13]; green travel [14]. However, there is little discussions of the promotion of college students' green consumption behavior in China. On this basis, this paper uses the TPB to further analyze the intentions of green consumption behavior of college students in real life. The hypotheses are proposed as follows:

$\mathrm{H}_{1}$ : Green consumption attitudes have a positive impact on green consumption intentions

$\mathrm{H}_{2}$ : Green consumption subjective norms have a positive impact on green consumption behavior

$\mathrm{H}_{3}$ : Green consumption perceived behavior controls have a positive impact on green consumption behavior

$\mathrm{H}_{4}$ : Green consumption intentions have a positive impact on green consumption behavior

\section{Methodology}

\subsection{Data Collection and Analysis}

Respondents are the students of a college in Hubei Province in China. A total of 1478 questionnaires were collected using convenience sampling, and 1439 valid questionnaires were used for the analysis. After data screening, a multiple regression analysis was employed using SPSS 20.0 to identify the relationships among the constructs.

\subsection{Measurement and Data Analysis}

In this study, the questionnaires were designed according to the relevant literature, and timely adjustment and revisions were undertaken to meet the requirements of the study. Items from prior research were used as the basis of measurement. Eight items were used to measure attitude toward the behavior; seven items were used to measure subjective norms. Perceived behavioral control was assessed using nine items. Five items were adapted to evaluate behavioral intention and actual behavior, respectively. Five-point Likert scales anchored by 1 (strongly disagree) and 5 (strongly agree) were used throughout the questionnaire.

\section{Research Results}

\subsection{Sample Characteristics}

The sample profile demonstrated that the highest proportion of students is in continuing school of education (64 percent), followed by school of accounting (22.6 percent), the school of tourism and hotel management (10.1 percent); and majority of the students were freshmen (71.9 percent).

\subsection{Empirical Results}

As shown in Table 1, all the Cronbach alpha coefficients range between 0.823 (attitude) and 0.913 (behavioral intentions) and thus exceed the suggested threshold of 0.70 [15]. Additionally, the highest mean score was observed for behavioral intentions, while the lowest mean score was on perceived behavioral controls.

As shown in Table 2, we conducted a Pearson's Correlation Analysis to realize the relationships among five constructs. The results of Pearson's Correlation Analysis demonstrated that behavioral intentions were highly significant to subjective norms and actual behavior, respectively. Attitude was significantly related to subjective norms. On the other words, most constructs had low relations with perceived behavior controls. 
Table 1. The Results of Mean, SD, Cronbach Alpha ( $n=1439)$

\begin{tabular}{lccc}
\hline \multicolumn{1}{c}{ Construct } & Mean & SD & $\alpha$ \\
\hline Attitude toward the behavior & 3.8503 & 0.5659 & 0.823 \\
Subjective norms & 3.9409 & 0.6413 & 0.898 \\
Perceived behavioral controls & 3.7646 & 0.6430 & 0.901 \\
Behavioral intentions & 4.0455 & 0.6678 & 0.913 \\
Actual behavior & 4.0096 & 0.6769 & 0.912 \\
\hline \hline
\end{tabular}

Note: SD: standard deviation; $\alpha$ : Cronbach alpha; CR: composite reliability; AVE: average variance extracted

Table 2. The Results of Pearson's Correlation Analysis $(n=1439)$

\begin{tabular}{llllll}
\hline \hline Construct & 1 & 2 & 3 & 4 & 5 \\
\hline $\begin{array}{l}\text { 1.Attitude toward the } \\
\text { behavior }\end{array}$ & & & & & \\
$\begin{array}{l}\text { 2. Subjective norms } \\
\text { 3. Perceived behavioral } \\
\text { controls }\end{array}$ & $0.759^{* *}$ & & & & \\
$\begin{array}{l}\text { 4. Behavioral intentions } \\
\text { 5. Actual behavior }\end{array}$ & $0.095^{* *}$ & $0.053^{*}$ & & & \\
\hline
\end{tabular}

Note: ${ }^{*}: p<0.05 ;^{* *}: p<0.01$

The results of multiple regression analysis showed that attitude $(\beta=0.216, p=0.000)$ and subjective norms $\left(\beta=0.374, p=0.000\right.$ ) had a positive impact on behavioral intentions, which supports $\mathrm{H}_{1}$ and $\mathrm{H}_{2}$. Perceived behavioral controls $(\beta=0.288, p=0.000$ ) was also found to have a significant impact on behavioral intentions. This supports $\mathrm{H}_{3}$. Behavioral intentions $(\beta=0.796, p=0.000)$ had a significant and positive relationship with actual behavior, providing support for $\mathrm{H}_{4}$.

\section{Discussion}

College students have a certain understanding of green consumption, but the specific practice is not clear. Students have a certain understanding of green consumption and understanding, but the specific content of the green consumption awareness is not enough, the consumption process of environmental protection and sustainable development of concern is not enough; from the green consumption action perspective, college students' spending habits of health degree and environmental protection is not high.

The perceptions of green consumption in college students are still weak. Although college students are receiving higher education, they do not receive systematic education or training specifically for green consumption. They learn about it only through the modern media network, advertising, television, and other means of the green understanding of consumer knowledge. Although the students can better gain the knowledge, because the information is not comprehensive and systematic, there are cognitive in college students for the green consumption.

College students' green consumption attitude is not clear, as they are still unstable. Most college students are willing to participate in environmental activities and willing to contribute their own efforts for environmental protection. However, not many realize that their consumption behavior has an impact on the environment. This shows that the green consumer attitudes of college students are not very clear, and the green consumption of college students is not through enough in-depth understanding.

The levels of green consumption of college students are still needed to enhance. At present, the price of green products is generally high, most students do not have personal income, most of the cost of living is borne by their parents, and thus, they do not want to spend a higher price to buy green products. Second, most college students find it difficult to identify markers such as the green product logo, which to a certain 
extent inhibit the green consumption of college students. College students' green consumption behavior level is low; they are mostly light green consumers, and their green consumption has potential. The current college students consider the quality and price factors as the most important while purchasing green products, and they give little consideration to environmental protection, as they are reluctant to pay a higher price for green products.

\section{Conclusion}

College students should broaden their access to green consumer information channels, enhance the level of green consumption awareness, and strengthen the attitude of green consumption. College students are the pillars of the future society; the sustainable development and construction of society has important responsibilities and obligations. From rom the lowest cost of green consumer behavior, and gradually cultivate and enhance the green consumer awareness. At the same time, college students should also influence their family and friends so that more people participate in green consumption.

Colleges and universities are the main channels for college students to acquire knowledge. Therefore, colleges and universities should set up lectures on green consumption or set up green-consumption-related courses, strengthen college students' environmental awareness and environmental attitudes, and further promote college students' green consumption willingness and behavior. Simultaneously, the schools should also set an example for students in the procurement of resources and equipment and buy green products as far as possible, so that students can feel the value of green products first-hand, which the future of green consumption of college students will have a positive role in promoting.

For enterprises, the current type of green products in China is relatively small, and the price is relatively high. Thus, enterprises should strengthen the development of green products and innovation, increase the variety of green products, improve technology, and reduce prices. Second, the enterprise for consumer consumption has a certain guiding role; companies can advertise or use public relations and other marketing activities to guide customers to green consumption. Especially for college students, who are a huge potential consumer group, they need to design suitable green products.

The government, as a market regulator, should increase the supervision of environmental protection and product safety efforts to prevent consumers from severe environmental issues in the market. Second, the government can formulate relevant fiscal and taxation policies to support and encourage enterprises to engage in green product research and development, innovation and promotion, so that it can improve the enthusiasm of enterprises to stimulate green consumers as well as upgrade the green industry.

\section{Acknowledgment}

This study was supported by Hubei University of Economics with the grant number of XJ16BS34. In addition, thanks to Miss Lu Guo, and Mr Cong $\mathrm{Mu}$ for their information collection and constructive suggestions for this study.

\section{References}

[1] Connoly, J., \& Prothero, A. (2008). Green consumption: Life-politics, risk and contradictions. Journal of consumer culture, 8, 117-145.

[2] Ainoa, J., Kaskela, A., Lahti, L., Saarikoski, N., Sivunen, A., Storgårds, J., \& Zhang, H. (2009). Future of living in. Bit Bang - Rays to the Future, pp. 174-204.

[3] Peattie, K. (2010), Green consumption: Behavior and norms. Annual Review of Environment and Resources, 35, 195-228.

[4] Haws, K. L., Winterich, K. P., \& Naylor, R. W. (2013), Seeing the world through green-tinted glasses: 
Green consumption values and responses to environmentally friendly products. Journal of Consumer Psychology, 24(3), 10.1016/j.jcps.2013.11.002.

[5] Ajzen, I., \& Fishbein, M. (1980). Understanding Attitudes and Predicting Social Behavior. Englewood Cliffs, London: Prentice-Hall.

[6] Fishbein, M., \& Ajzen, I. (1975). Belief, attitude, intention, and behavior: An introduction to theory and research. Reading. Mass, London: Addison-Wesley.

[7] Ajzen, I. (1985). From intentions to actions: A theory of planned behavior. Action-Control: From Cognition to Behavior, 11-39.

[8] Ajzen, I. (1991). The theory of planned behavior. Organizational Behavior and Human Decision Processes, 50, 179-211.

[9] Ajzen, I. (2005). Attitudes, Personality, and Behavior. New York: Open University Press.

[10] Fielding, K. S., McDonald, R., \& Louis, W. R. (2008). Theory of planned behaviour, identity and intentions to engage in environmental activism. Journal of Environmental Psychology, 28(4), 318-326.

[11] Dahlstrom, R. H. (2011). Green Marketing Management. Mason, O.H: South-Western Cengage.

[12] Moreo, A. (2008). Green Consumption in the Hotel Industry: An Examination of Consumer Attitudes. Newark: University of Delaware.

[13] Carrus, G., Passafaro, P., \& Bonnes, M. (2008). Emotions, habits and rational choices in ecological behaviours: The case of recycling and use of public transportation. Journal of Environmental Psychology, 28, 51-62.

[14] Vega-Zamora, M., Torres-Ruiz, F. J., Murgado-Armenteros, E. M., \& Parras-Rosa, M. (2014). Organic as a heuristic cue: What Spanish consumers mean by organic foods. Psychology \& Marketing, 31(5), 349-359.

[15] Nunnally, J. C. (1978). Psychometric Theory (2 ed.). New York: McGraw-Hill.

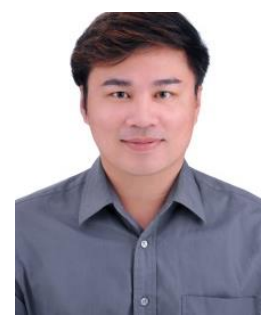

Chih-Hsuan Huang received his Ph.D. in consumer behavior from Queensland University of Technology, Brisbane, Australia in 2013. He is a Lecturer in the School of Business Administration at Hubei University of Economics, Wuhan City, China.

He was elected as an International Economics Development Research Center (IEDRC) Fellow Member in Jan. 2016. He is a Technical Program Committee for 2017 International Conference on Economic Development and Enterprise Innovation (EDEI) and 2017 International Conference on Financial Technology (ICFT). Moreover, he serves as Reviewer for INQUIRY: The Journal of Health Care Organization, Provision, and Financing (indexed in Science Citation Index). His research in these areas has appeared in a journal such as Asia Pacific Journal of Marketing and Logistics, International Journal of Health Care Quality Assurance, Journal of Management Research, Asia Journal of Business and Management, Journal of Computing and Information Science in Engineering, etc. His research interests include green consumer behavior, relationship marketing, sustainable management and patient safety.

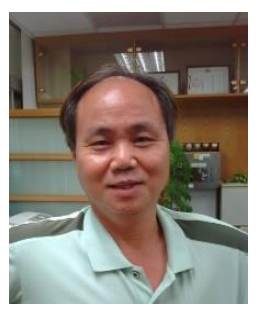

Yi-Chun Huang is professor, Dept. of Business Administration National Kaohsiung University of Applied Sciences, Taiwan. His papers have published in management decision, Journal of Management and Organization, Production and Planning Control, Management Research Review, Marketing Intelligence \& Planning, International Journal of Physical Distribution \& Logistics Management, Supply Chain Management: an International Journal, etc..... His research interests include logistics, reverse logistics, 
marketing management, and green innovative strategy. He received his Ph.D. degree in Business Administration from National Sun Yat-Sen University, Taiwan.

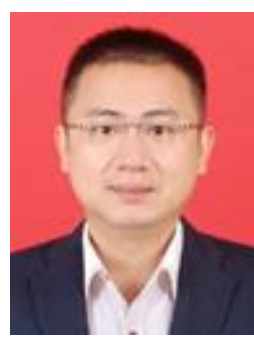

Hong Jin received his Ph.D. in management science and engineering from Wuhan University of Technology, Wuhan City, China in 2011. He is an associate professor in the School of Business Administration at Hubei University of Economics (HBUE), Wuhan City, China. He is a dean of the Marketing Department in College of Business Administration at HBUE. His research interests include business model innovation, strategic innovation and management.

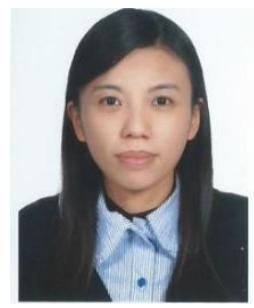

Meng-Chen Lin is a lecturer in the School of Business Administration at Hubei University of Economics, Wuhan City, China. She earned her Ph.D. degree from National Dong Hwa University in 2016. Her research areas include marketing management, e-commerce, lean service and strategic. She has published 19 papers at international and domestic academic journals and conferences. Meng-Chen Lin received his Ph.D. in marketing management from Yuan Ze University, Taiwan in 2016. She is a Lecturer in the School of Business Administration at Hubei University of Economics, Wuhan City, China. Her research in these areas has appeared in a Journal of Marketing Management, Chung Yuan Management Review, etc. Her research interests include consumer behavior, relationship marketing, internet marketing, and marketing strategy.

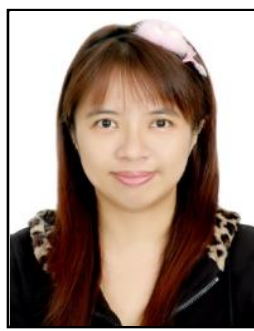

Yu-Ping Wu is a lecturer in the School of Business Administration at Hubei University of Economics, Wuhan City, China. She earned her Ph.D. degree from National Dong Hwa University in 2016. Her research areas include marketing management, e-commerce, lean service and strategic. She has published 19 papers at international and domestic academic journals and conferences.

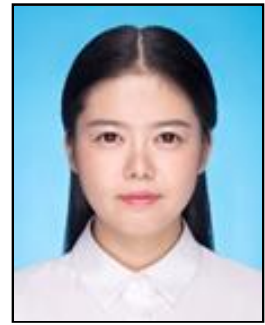

Li Lee is a lecturer in the School of Management at Wuhan Institute of Bioengineering, Wuhan City, China. She earned her master degree from Hubei University of Economics in 2017. Her research areas include relationship marketing and stock incentive compensation, and patient safety culture. 